\title{
Dissolved organic matter in sea spray: a transfer study from marine surface water to aerosols
}

\author{
P. Schmitt-Kopplin ${ }^{1,2}$, G. Liger-Belair ${ }^{3}$, B. P. Koch ${ }^{4,5}$, R. Flerus ${ }^{4}$, G. Kattner ${ }^{4}$, M. Harir ${ }^{1}$, B. Kanawati ${ }^{1}$, M. Lucio ${ }^{1}$, \\ D. Tziotis ${ }^{1}$, N. Hertkorn ${ }^{1}$, and I. Gebefügi ${ }^{1}$ \\ ${ }^{1}$ Research Unit Analytical Biogeochemistry, Helmholtz Zentrum München, Ingolstädter Landstr. 1, \\ 85764 Neuherberg, Germany \\ ${ }^{2}$ Chair of Analytical Food Chemistry, Technische Universität München, 85354 Freising-Weihenstephan, Germany \\ ${ }^{3}$ Equipe Effervescence, Groupe de Spectrométrie Moléculaire et Atmosphérique (GSMA), UMR6089, \\ CNRS - UFR Sciences Exactes et Naturelles, BP 1039, 51687 Reims Cedex 2, France \\ ${ }^{4}$ Alfred Wegener Institute for Polar and Marine Research, Ecological Chemistry, Am Handelshafen 12, \\ 27570 Bremerhaven, Germany \\ ${ }^{5}$ University of Applied Sciences, 27568 Bremerhaven, Germany
}

Correspondence to: P. Schmitt-Kopplin (schmitt-kopplin@helmholtz-muenchen.de)

Received: 15 November 2011 - Published in Biogeosciences Discuss.: 8 December 2011

Revised: 28 March 2012 - Accepted: 28 March 2012 - Published: 27 April 2012

\begin{abstract}
Atmospheric aerosols impose direct and indirect effects on the climate system, for example, by absorption of radiation in relation to cloud droplets size, on chemical and organic composition and cloud dynamics. The first step in the formation of Organic primary aerosols, i.e. the transfer of dissolved organic matter from the marine surface into the atmosphere, was studied. We present a molecular level description of this phenomenon using the high resolution analytical tools of Fourier transform ion cyclotron resonance mass spectrometry (FT-ICR MS) and nuclear magnetic resonance spectroscopy (NMR). Our experiments confirm the chemoselective transfer of natural organic molecules, especially of aliphatic compounds from the surface water into the atmosphere via bubble bursting processes. Transfer from marine surface water to the atmosphere involves a chemical gradient governed by the physicochemical properties of the involved molecules when comparing elemental compositions and differentiating $\mathrm{CHO}, \mathrm{CHNO}, \mathrm{CHOS}$ and CHNOS bearing compounds. Typical chemical fingerprints of compounds enriched in the aerosol phase were $\mathrm{CHO}$ and CHOS molecular series, smaller molecules of higher aliphaticity and lower oxygen content, and typical surfactants. A nontargeted metabolomics analysis demonstrated that many of these molecules corresponded to homologous series of oxo-, hydroxy-, methoxy-, branched fatty acids and mono-, di-
\end{abstract}

and tricarboxylic acids as well as monoterpenes and sugars. These surface active biomolecules were preferentially transferred from surface water into the atmosphere via bubble bursting processes to form a significant fraction of primary organic aerosols. This way of sea spray production leaves a selective biological signature of the surface water in the corresponding aerosol that may be transported into higher altitudes up to the lower atmosphere, thus contributing to the formation of secondary organic aerosol on a global scale or transported laterally with possible deposition in the context of global biogeocycling.

\section{Introduction}

On a large scale, sea spray, which transports dissolved gases, salts, and biological materials from the sea to the atmosphere with resulting climatic impact, is largely attributed to aerosols produced by an estimated $10^{18}$ to $10^{20}$ bubbles that rupture every second across the oceans (Woodcock et al., 1953; MacIntyre, 1972; Wu, 1981). Marine aerosols account for a high amount of the global natural aerosol flux and consequently may have a significant impact on the Earth's radiative balance and biogeochemical cycling (O'Dowd et al., 2004; O’Dowd and de Leeuw, 2007). 
Preferential enrichment of surfactants at the air-water interface occurs as a result of the amphiphilic properties of surfactants, with the water-soluble moiety plunging into the solution and the hydrophobic component exposed to the atmosphere. Selective enrichment of specific surfactant materials - in the sea-surface microlayer and in atmospheric aerosols has been well described (Barger and Garret, 1970; Mukerjee and Handa, 1981; Blanchard, 1990; Tseng et al., 1992; Oppo et al., 1999; Ekström et al., 2010). This enrichment of surfactants is even more increased at the sea surface during rough sea conditions, when wave breaking action causes air bubbles to be trapped beneath the water surface (O'Dowd and de Leeuw, 2007). Bubbles trapped in the liquid bulk considerably increase exchange surfaces between the sea bulk and the atmosphere. Bubbles drag surfactants along their way through the liquid bulk, reach the sea surface, to finally burst and eject aerosol droplets into the atmosphere; the principle is similar to adsorptive bubble separation in foaming systems (Backleh-Sohrt et al., 2005). Since these droplets formed from the sea surface and immediate subsurface water layers are enriched with surface active compounds, aerosols emitted into the atmosphere are also enriched with surface active materials compared to the liquid bulk. Air bubbles trapped during rough sea conditions were found to increase surfactant concentrations in aerosols by several orders of magnitude compared with those found in the liquid bulk (O'Dowd and de Leeuw, 2007). Recently, Bird et al. (2010) proved that, by rupturing, a single large bubble (with several centimeters in diameter) can form and entrap air as it retracts, thus leading to the creation of a ring of small daughter millimetric bubbles, which burst in turn (Bird et al., 2010). This phenomenon is believed to considerably increase the inner active surface and efficiency of aerosol dispersal.

From a conceptual point of view, the situation found in glasses poured with Champagne or sparkling wine is very similar to that described above. As soon as a bottle of Champagne or sparkling wine is uncorked, the progressive release of $\mathrm{CO}_{2}$ and other dissolved gas molecules is responsible for bubble nucleation, the so-called effervescence process (Liger-Belair, 2003). Once Champagne is poured into a glass, bubbles nucleated on the glass wall drag Champagne surfactants along their way through the liquid bulk (LigerBelair et al., 2000). The formation of adsorption layers of amphiphilic macromolecules at the air/Champagne interface was evidenced through ellipsometry and Brewster angle microscopy (BAM) experiments (Péron et al., 2001, 2004).

Generally speaking, bubbles bursting at a liquid surface eject two kinds of aerosols (Resch et al., 1986 and references therein): (i) droplets called film drops, formed while the film of the emerged bubble-cap disintegrates, and (ii) droplets formed by the collapse of the bottom of the bubble, called jet drops (see Fig. 1). Depending on its size, a bubble can produce up to ten jet drops and several hundreds of film drops. Nevertheless, it was shown that bubbles with a diameter of less than about $2 \mathrm{~mm}$ produce no film drops as they burst

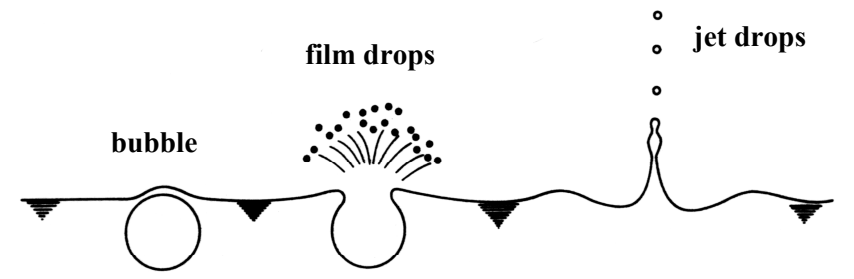

Fig. 1. Scheme of the two production ways of droplets from a bursting bubble; redrawn from Resch et al. (1986).

(Resch et al., 1986). In the case of marine waters, bubble diameters rarely exceed about $1 \mathrm{~mm}$ as they reach the liquid surface, and it can be concluded that only jet drops constitute the very characteristic cloud of aerosols found above the liquid surface, as revealed through high-speed micrography (Liger-Belair et al., 2001).

The aim of this study of marine aerosol formation was the qualitative molecular level characterization of the aerosol produced by bubbles collapsing in a specifically-designed bursting chamber and its comparison with both the original sea surface water and the organic aerosol (particle size $\mathrm{PM}_{10}$ ) collected on the deck of the research vessel. The transfer of the organic signature from surface water into the burst event and the atmospheric aerosol in general was followed over all samples of the cruise and on a specific open ocean site in the Angola Basin $\left(3.1^{\circ} \mathrm{E}, 17.7^{\circ} \mathrm{S}\right)$. The focus was on the characterization of the specific molecular structures involved in the preferential transfer and the corresponding biomolecules involved, leading to the formation of the marine primary organic aerosol. The methods used were Fourier transform ion cyclotron resonance spectrometry (FT-ICR MS) and nuclear magnetic resonance spectroscopy (NMR).

High field FT-ICR mass spectrometry analyzes molecular ions with ultrahigh resolution and excellent sensitivity and allows the assignment of thousands of molecular formulas out of complex mixtures (Hertkorn et al., 2008). Recently, own-developed network analysis (Tziotis et al., 2011) has decisively enlarged the coverage of molecular formula assignment from FT-ICR MS spectra. NMR spectroscopy offers isotope-specific and unsurpassed information about short-range atomic order, which is absolutely indispensable for any de novo structural analysis. In very complex mixtures of unknowns, NMR is the most suitable profiling tool with an optimum combination of quantification and structural significance.

\section{Materials and methods}

\subsection{Study sites and sampling}

Water samples were collected daily on the research vessel Polarstern during the expedition ANT-XXV/1 between Bremerhaven, Germany and Cape Town, South Africa from 3 to 

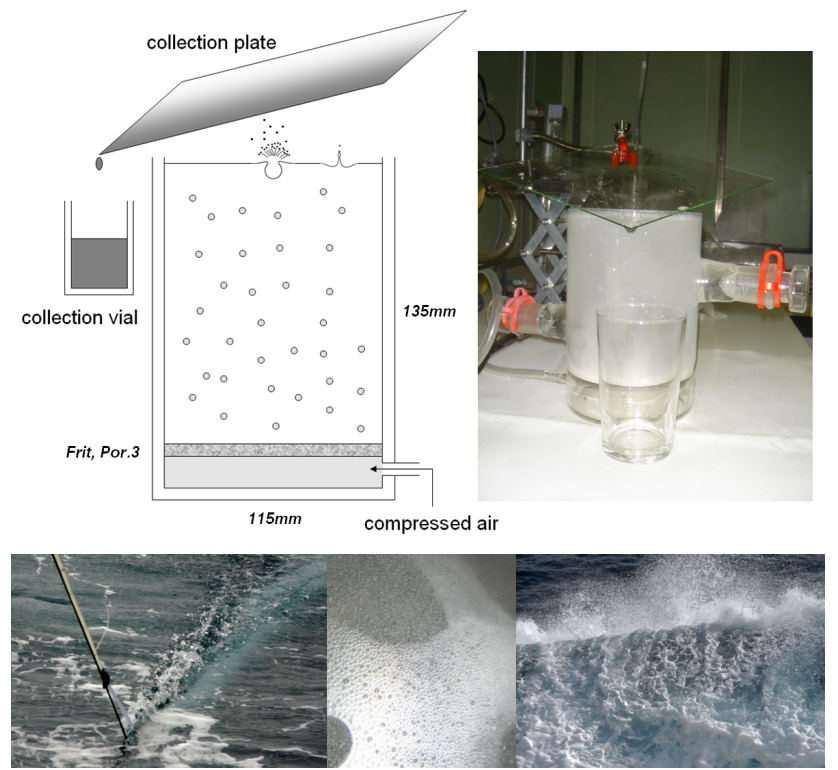

Fig. 2. Apparatus used for the generation and collection of the burst generated freshly from the surface water. The water was collected with the "fish" sampler in the surface of the water layer (left); bursting bubbles at the surface of the chamber (middle) and on sea water surface of the ocean (right).

29 November 2008. The selected day sample for surface water, sea spray generation and day aerosol was chosen at the Angola Basin ( 27 November 2008 at $\left.3.1^{\circ} \mathrm{E}, 17.7^{\circ} \mathrm{S}\right)$, i.e. at the same location in which NOM in surface water has been characterized in great detail (Hertkorn et al., 2012). During the expedition, no heavy rain showers occurred in the Intertropical Convergence Zone (ITCZ), although intense rainfall is common in this region; thus the collection of surface water with the fish sampler generated representative surface water for analysis and for the production of burst in the laboratory on board (Fig. 2). The water was filtered through pre-combusted $\left(4 \mathrm{~h}, 450{ }^{\circ} \mathrm{C}\right) \mathrm{GF} / \mathrm{F}$ filters (Whatman) as described by Flerus et al. (this issue) prior to further solid phase extraction (SPE) and bursting.

\subsection{Bubble bursting chamber}

Following filtration in the laboratory on the research vessel, the sea spray was immediately generated by bursting of surface water with a hand-made device (Fig. 2). The bubble bursting chamber was initially built to enable the bursting of a continuous flow of fresh water introduced in counter flow, but was used here in a static mode with around $1500 \mathrm{ml}$ freshly filtered seawater each day. The number, size, and velocity of jet drops produced during bubble collapse depend on both the size of the initial bursting bubble and some physical liquid properties such as its surface tension, density and viscosity (Spiel, 1994, 1995, 1997); it is to be noted here that the bubble size and the foaming/bursting behavior (as well as chemical selectivity) of the sea water in the constructed vessel were very similar to the one with Champagne in our previous study (Liger-Belair et al., 2009).

Briefly, the jet drops were collected on a glass surface on the top of the vessel, oriented in a way to drop the liquid into a collecting vial at the corner. After $2 \mathrm{~h}$ of sampling, the glass surface, also containing dried jets, was washed with distilled water into the collecting vial. This final solution was desalted and concentrated using SPE as described below.

\subsection{Solid phase extraction (SPE)}

FT-ICR MS measurement requires the concentration and desalting of marine dissolved organic matter (DOM) prior to infusion analysis. Therefore, DOM was extracted on board using reverse phase solid phase extraction (SPE). The filtered samples were acidified by $\mathrm{HCl}$ (hydrochloric acid, p.a. grade, Merck) to $\mathrm{pH} 2$. The DOM was extracted using C18-SPE cartridges $(100 \mathrm{mg} / 1 \mathrm{ml}$ Bakerbond SPE columns, J. T. Baker, The Netherlands). The cartridges were rinsed with $1 \mathrm{ml}$ methanol (LiChrosolv; Merck), followed by $1 \mathrm{ml}$ acidified ultra-pure water ( $1.25 \%$ formic acid) for conditioning, and then the water samples were passed through each cartridge by gravity. Subsequently, remaining salt was removed with $1 \mathrm{ml}$ acidified ultra-pure water. DOM was eluted with $5 \mathrm{ml}$ methanol and stored in Eppendorf vials at $-20^{\circ} \mathrm{C}$. The surface water DOM was extracted with SPE from $1000 \mathrm{ml}$ water samples, and the burst DOM with SPE from all the volume collected in the vials (around $10 \mathrm{ml}$ ). A blank SPE extract was generated and analyzed with FTICR MS mass spectrometry to make sure the signals obtained with this procedure actually originated from the DOM.

\subsection{Aerosol collection and water soluble organic matter (WSOM) extraction}

Particle sampling: fine $\left(d_{\mathrm{p}}<10 \mu \mathrm{m}, \mathrm{PM}_{10}\right)$ aerosol samples were collected on circular quartz fiber filters $(4.5 \mathrm{~cm}$ diameter, fiber glass; Whatman, pre-combusted $4 \mathrm{~h}$ at $450^{\circ} \mathrm{C}$ ) with a low volume sampler (constructed by Ingenieurbüro Schulze, 21271 Asendorf, Germany) as described previously by Piel et al. (2006). The collector was placed at the front of the vessel at the upper deck ( $20 \mathrm{~m}$ above the sea). Approximately $60 \mathrm{~m}^{3}$ were collected every $12 \mathrm{~h}$, and the day and night samples were sampled separately. Only day filters were considered in this study. The filters were immediately placed in small Petri dishes and stored at $-20^{\circ} \mathrm{C}$ prior to their SPE extraction with $\mathrm{C} 18$ at the Helmholtz Center in Munich, as described in a previous work on aerosol (Schmitt-Kopplin et al., 2010). Note that identical C18-SPE cartridges were used to obtain organic matter from water and burst samples as well as from aerosols.

SPE-C18 extraction of aerosol: the quartz filters $\left(1 \mathrm{~cm}^{2}\right.$ punched with the cap of $2 \mathrm{ml}$ Eppendorf vials) were extracted in slight alkaline conditions $\left(1.25 \%\right.$ aqueous $\left.\mathrm{NH}_{3}\right)$. 
Subsequent SPE was made using $100 \mathrm{mg}$ Bakerbond C18 cartridges (J. T. Baker, The Netherlands). The cartridges were conditioned with $1 \mathrm{ml}$ of methanol and $1 \mathrm{ml}$ of water acidified with formic acid (1.25\% aqueous formic acid). After application of $1 \mathrm{ml}$ of sample (acidified with $50 \mu \mathrm{l}$ formic acid), the columns were washed with the acidified water. The compounds were eluted with $1 \mathrm{ml}$ methanol and were then ready for infusion analysis.

\subsection{FT-ICR mass spectrometry}

Ultrahigh-resolution mass spectra were acquired on a Bruker (Bremen, Germany) APEX 12Qe Fourier transform ion cyclotron resonance mass spectrometer (FT-ICR MS) equipped with a 12 Tesla superconducting magnet and an APOLLO II electrospray source. Samples were introduced into the microelectrospray source (Agilent sprayer) at a flow rate of $120 \mu \mathrm{h}^{-1}$ with a nebulizer gas pressure of $20 \mathrm{psi}$ and a drying gas pressure of $15 \mathrm{psi}\left(250^{\circ} \mathrm{C}\right)$. Spectra were externally calibrated on clusters of arginine $\left(2.87 \times 10^{-5} \mathrm{moll}^{-1}\right)$ and the mass accuracy reached values below $0.1 \mathrm{ppm}$ in dayto-day measurements. The spectra were acquired with a time domain of 4 megawords in a mass range of $\mathrm{m} / \mathrm{z} 100$ 2000. Before Fourier transformation of the time-domain transient, a sine apodization was performed. 1024 scans were accumulated for each sample.

FT-ICR mass spectra with $\mathrm{m} / \mathrm{z}$ from 150 to 2000 were exported to peak lists at a signal to noise ratio of 2. Possible elemental formulas were calculated for each peak in batch mode by the FormCalc software tool written in-house and with the NetCalc network approach described previously (Tziotis et al., 2011). Here, we use the mass-mass difference information obtained from the FT-ICR mass spectra and a list of pre-chosen molecular transformations in order to reconstruct three compositional networks corresponding to surface, aerosol, and burst samples, respectively. Those networks, which are rich in compositional information, are then combined into a single network with the purpose of detecting the common masses between the three systems and visualizing their interactions. The algorithm performs a network-based formula calculation on each of those networks. Using the newly-found elemental compositions, further network analysis is illustrated via the compositional frequency histograms. The generated formulas were validated by setting sensible chemical constraints ( $\mathrm{N}$ rule, positive double bond equivalent, $\mathrm{O} / \mathrm{C}$ ratio $\leq 1, \mathrm{H} / \mathrm{C}$ ratio $\leq 2 n+2$; element counts: $\mathrm{C} \leq 20, \mathrm{H} \leq 30, \mathrm{O} \leq 6, \mathrm{~N} \leq 5, \mathrm{~S} \leq 1)$. The software uses theoretical isotope scoring in conjunction with an elemental composition calculator to score comparison of experimental and theoretical isotope patterns. From the lists of $\mathrm{m} / z$, lists of final formulas (from 1500 to 3000 hits) could be generated and classified in containing $\mathrm{CHO}$ (blue), CHNO (orange), CHOS (green) or CHNOS (red) molecules in Figs. 3-6.
A metabolomics web-interface called MassTRIX (www.MassTRIX.org) developed by Suhre and SchmittKopplin (2008) for systems biology studies was used for the annotation of the experimental exact masses into pathways. This approach uses the advantage of sub-ppm masses accuracy of FT-ICR MS mass spectrometry to relate the MS data within the confidence interval set to $\pm 0.5 \mathrm{ppm}$ to all metabolites described in available biological databases. For this, the Kyoto Encyclopedia of Genes and Genomes (KEGG) and LipidMap databases enabled a description of hundreds of metabolites and their representation in pathways for the characterization of the biosignatures.

\subsection{Nuclear magnetic resonance spectroscopy (NMR)}

NMR spectra of methanolic aerosol extracts were acquired with a Bruker Avance NMR spectrometer at $500.13 \mathrm{MHz}$ $\left(B_{0}=11.7 \mathrm{~T}\right)$ at $283 \mathrm{~K}$ from a few $\mu \mathrm{g}$ of solid obtained by evaporation of original methanol- $\mathrm{h}_{4}$ solution. Proton NMR spectra were acquired in approx. $70 \mu \mathrm{CD}_{3} \mathrm{OD}$ (Merck, $99.95 \%{ }^{2} \mathrm{H}$ ) solution with a $5 \mathrm{~mm}$ z-gradient ${ }^{1} \mathrm{H} /{ }^{13} \mathrm{C} /{ }^{15} \mathrm{~N}$ TXI cryogenic probe in sealed $2 \mathrm{~mm}$ Bruker MATCH tubes. 1D ${ }^{1} \mathrm{H}$ NMR spectra were recorded with standard presaturation to attenuate residual water present $\left(90^{\circ}\right.$ excitation pulses ${ }^{1} \mathrm{H}$ : $10 \mu \mathrm{s}, 5 \mathrm{~s}$ acquisition time, $5 \mathrm{~s}$ relaxation delay, typically 256-512 scans, $1 \mathrm{~Hz}$ exponential line broadening). A phase sensitive, gradient enhanced COSY NMR spectrum with solvent suppression (cosydfgpph19) was acquired with a Bruker Avance NMR spectrometer at $500.13 \mathrm{MHz}\left(B_{0}=11.7 \mathrm{~T}\right)$ at $283 \mathrm{~K}$ with an acquisition time of $1 \mathrm{~s}$, a relaxation delay of $0.5 \mathrm{~s}$, a spectral width of $6493 \mathrm{~Hz}(12.5 \mathrm{ppm})$ with time proportional phase increment (TPPI). 400 scans and 569 increments were acquired and computed in absolute value mode to a $16 \mathrm{k} \times 1024$ matrix, with $2.5 \mathrm{~Hz}$ exponential multiplication in F2 and an unshifted sine bell in F1.

\section{Results and discussion}

The sea spray transport of DOM to the atmosphere was analyzed in the laboratory on the ship with fresh marine water samples and we present the qualitative description of the organic fractionation during the passage from the surface water into the formed burst droplets toward the aerosols. An oceanic air and surface water transfer study of pollutants with hexachlorocyclohexanes Xie et al.(2011) already demonstrated the presence of deposition and volatilization processes. Here, we focus on chemical structural changes, depletions and enrichments in the process of primary marine aerosol formation via the bubble bursting process. The structural description of the organic material transferred to the atmosphere is based on FT-ICR mass spectrometry and NMR spectroscopy. 

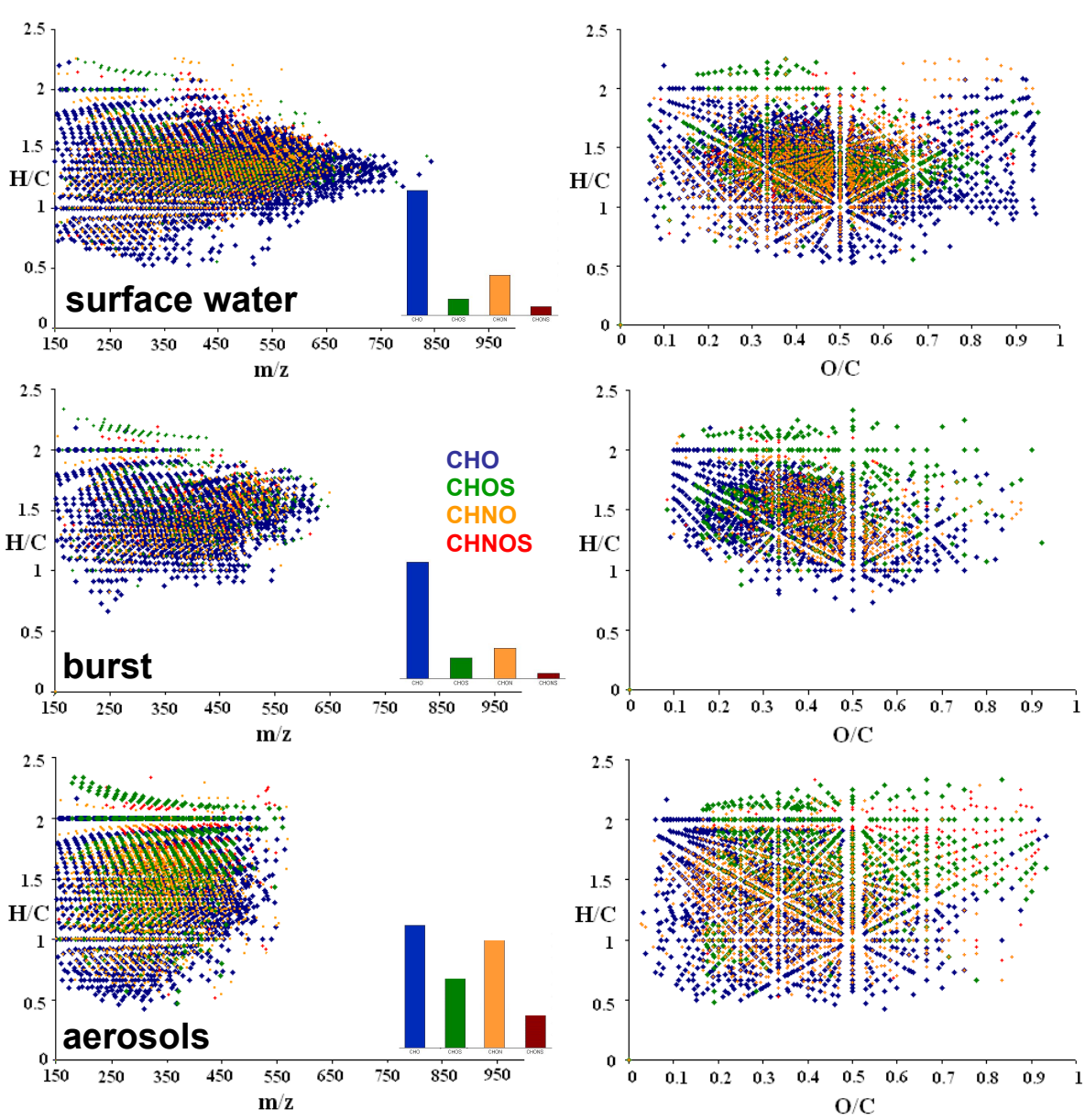

Fig. 3. Representation of of the FTI-CRMS data as van Krevelen diagrams (right panels) with of all the surface all burst and all day aerosol cumulated mass data over the entire cruise ANT-XXV/1. Left panels represent the $\mathrm{m} / \mathrm{z}$ dependant H/C values and the relative frequency histograms of CHO (blue), CHOS (green), CHNO (orange) and CHNOS (red) compounds.

The analysis of all FT-ICR mass signals within surface water, burst and day time aerosol samples is presented in Fig. 3. The van Krevelen diagram for the surface water mainly showed $\mathrm{CHO}$ and $\mathrm{CHNO}$ type compounds up to an $\mathrm{m} / \mathrm{z}$ range of 800 . At higher $\mathrm{O} / \mathrm{C}$ and $\mathrm{H} / \mathrm{C}$ ratios, carbohydrate type compounds were also ionized. The cumulated burst samples had lower masses up to $m / z \sim 600$ with a lower aromatic content, a relative increase in CHOS and a depletion of CHNO compounds. The cumulated data of all day aerosols reflected a typical aerosol fingerprint with mainly low mass values up to $m / z \sim 500$. These aerosols showed an increased proportion of aromatic CHNO and CHOS molecular series, indicating anthropogenic input by biomass burning or ship exhaust as well as considerable levels of sulfonated secondary organic aerosols (SOA) in analogy to SOA described earlier in Schmitt-Kopplin et al. (2010).

To extract the $\mathrm{m} / \mathrm{z}$ values that commonly occurred in surface and burst samples and those that showed an average increase/depletion in the burst relative to the surface samples, we followed the same data evaluation procedure as described in the chemical description of Champagne aerosol in LigerBelair et al. (2009). Here, we observed a clear relative increase in the intensity of mainly CHO-compounds of higher aliphaticity and lower oxygen content (Fig. 4). This is in accordance with the previous study in which surface active compounds and fatty acids were shown to be preferentially concentrated in the formed jets. In addition, many other compounds with a high binding affinity to those surfactants were co-fractionated and concentrated as well.

To verify this natural fractionation process, we selected a particular sampling point in the Angola Basin (27 November 2008 at $3.1^{\circ} \mathrm{E}, 17.7^{\circ} \mathrm{S}$ ), in which surface water has been also studied in great detail by NMR spectroscopy and FTICR MS mass spectrometry (Hertkorn et al., 2012). The surface water layer and the aerosols of this sampling site were characteristic of pristine open ocean (Fig. 5), with no anthropogenic organic signatures as found in the van Krevelen diagram of all transect data in Fig. 3 (characteristic aromatic signatures corresponding to ship or industrial emissions were absent). The surface water showed the typical 

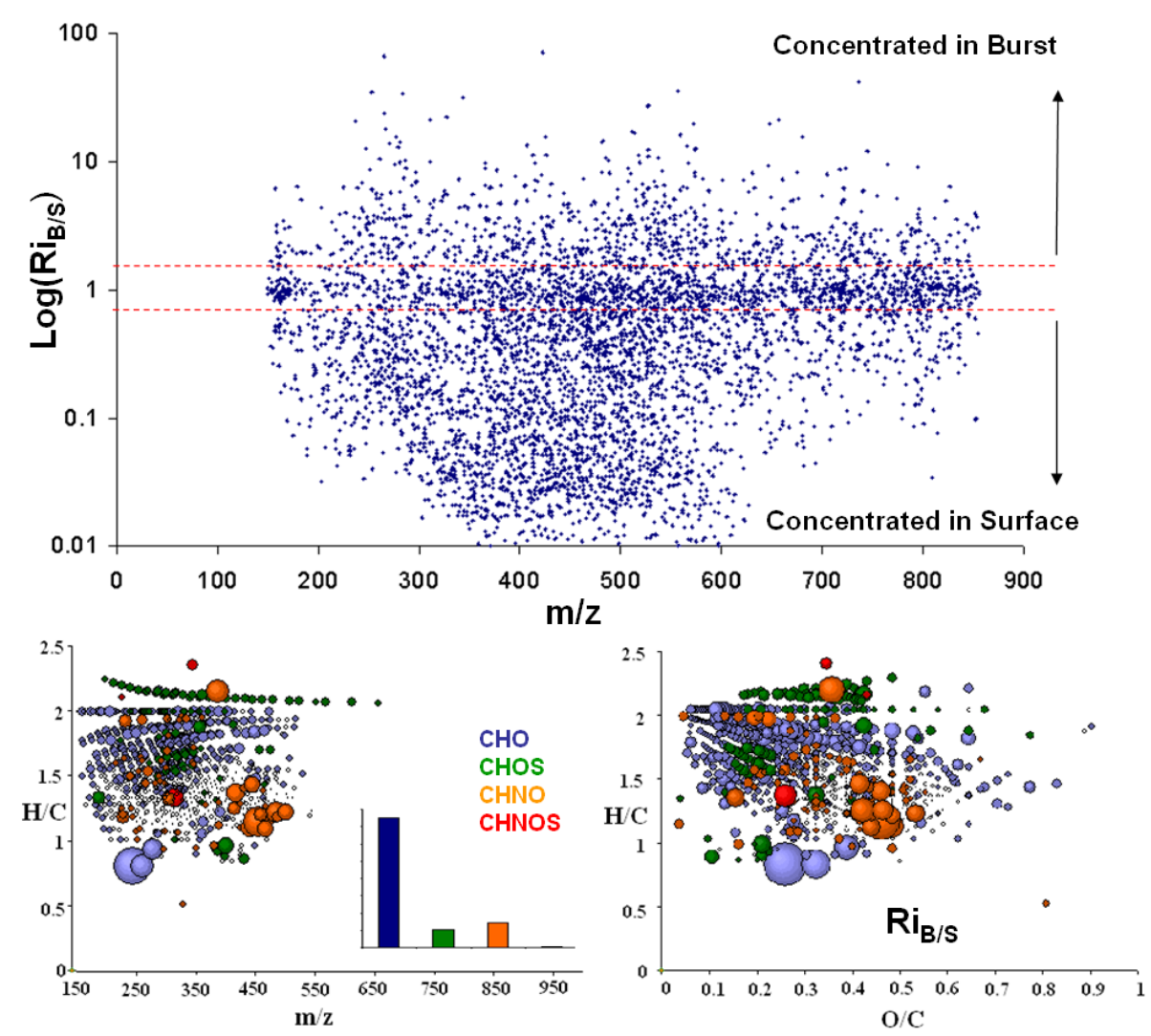

Fig. 4. Analysis of all burst $(B)$ data versus all surface $(S)$ data based on the intensity ratios (RiB/S) of $m / z$ within 1 ppm similarity windows. Differentiation of the $\mathrm{m} / \mathrm{z}$ intensity enhanced $(\mathrm{RiB} / \mathrm{S}>2)$ or depleted $(\mathrm{RiB} / \mathrm{S}<2)$ in the burst relative to the surface as illustrated in the van Krevelen diagrams (circle size in the graphs was proportional to the intensity ratios RiB/S). The ratio increased from higher oxygen content towards lower $\mathrm{O} / \mathrm{C}$ and from lower $\mathrm{H} / \mathrm{C}$ values (unsaturated and aromatic compounds) towards higher H/C (saturated, aliphatic).

distribution of marine DOM near average $\mathrm{H} / \mathrm{C}$ and $\mathrm{O} / \mathrm{C}$ values, for which the largest number of isomeric molecules is expected (Hertkorn et al., 2007). This section also hosts the carboxylic rich alicyclic (CRAM) organic fraction (Hertkorn at al., 2006), which represents highly transformed organic matter. Accordingly, the corresponding compositional network was very compact, representative of an extensive connectivity in involved mass differences. The burst accumulated mainly $\mathrm{CHO}$ and a few CHOS compounds and lesser CHNO compounds; this is also visible in the looser structural network representation. Finally, the aerosol fraction showed a relative increase in surface active compounds of $\mathrm{CHO}$ and CHOS type in comparison with the surface water. The corresponding compositional network was much looser, showing fewer connectivities corresponding to a less transformed organic material, probably of mainly biological origin. The mass range followed the same trend as in Fig. 3 with lower $\mathrm{m} / \mathrm{z}$ values in the order surface/burst/aerosol (not shown in figure).

Figure 6 integrates the whole $\mathrm{m} / \mathrm{z}$ information within all the stations of the cruise in compositional networks showing the same trends of progressively looser networks in the order surface/burst/aerosol, corresponding to lower overall chemical diversity. In addition, we used this approach to integrate the datasets from these three fractions and highlighted the common masses in all three types of samples.

The three Angola Basin DOC samples were analyzed by NMR spectroscopy (Fig. 7). All NMR spectra were characterized by large and distinct NMR resonances in the aliphatic section $\delta_{\mathrm{H}} \sim 0.5 \ldots 4.3 \mathrm{ppm}$, indicating a suite of several abundant small spin systems containing aliphatic and oxygenated units with nicely resolved couplings. Polymethylene NMR resonances $\left(\delta_{\mathrm{H}} \sim 1.28 \mathrm{ppm}\right)$ were abundant in all samples, especially in the aerosol sample where they contributed almost $50 \%$ of the entire proton NMR integral (Table 1). The ratio of methyl to polymethylene, an indicator of "pure" aliphatic branching $\left(\mathrm{H}_{3} \mathrm{C}-\mathrm{C}-\mathrm{C}-\mathrm{Z}\right.$, with any heteroatom $\mathrm{Z}$ at least four bonds away from methyl protons), grew in the order aerosol $<$ surface water $<$ burst; i.e. aliphatics appeared most branched in the burst sample. This was corroborated by a parallel increase of functionalized aliphatics with $\delta_{\mathrm{H}} \sim 1.35 \ldots 1.9 \mathrm{ppm}$, which here followed the order aerosol $<$ burst $<$ surface water. Oxygenation, i.e. the occurrence of $\mathrm{HCO}$ substructures, was maximal in surface 

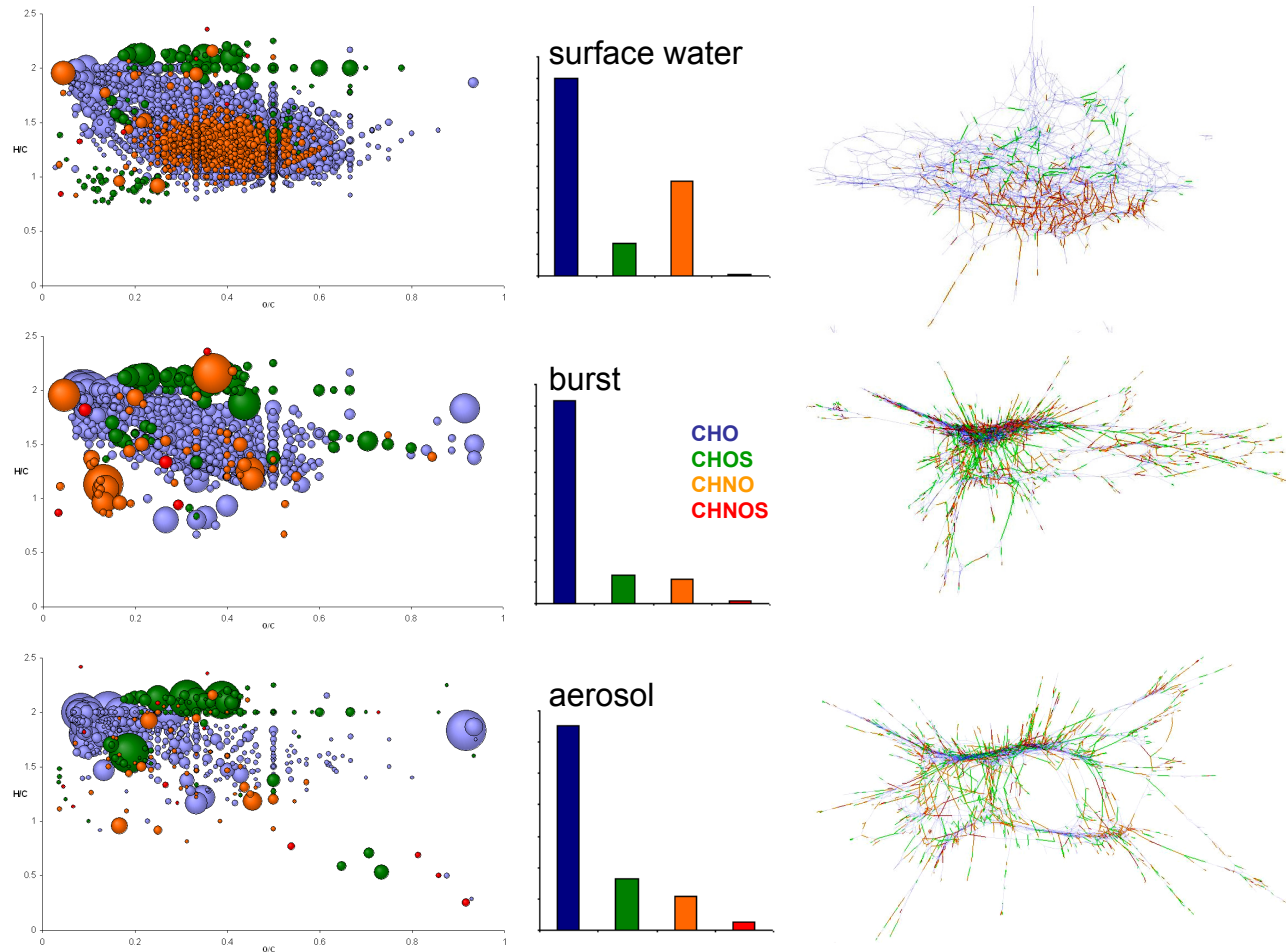

Fig. 5. Sampling day 27 (Angola Basin) represented as van Krevelen diagrams of the surface, burst and day aerosol samples and corresponding compositional frequency histograms and corresponding compositional networks (color code as in previous figures).
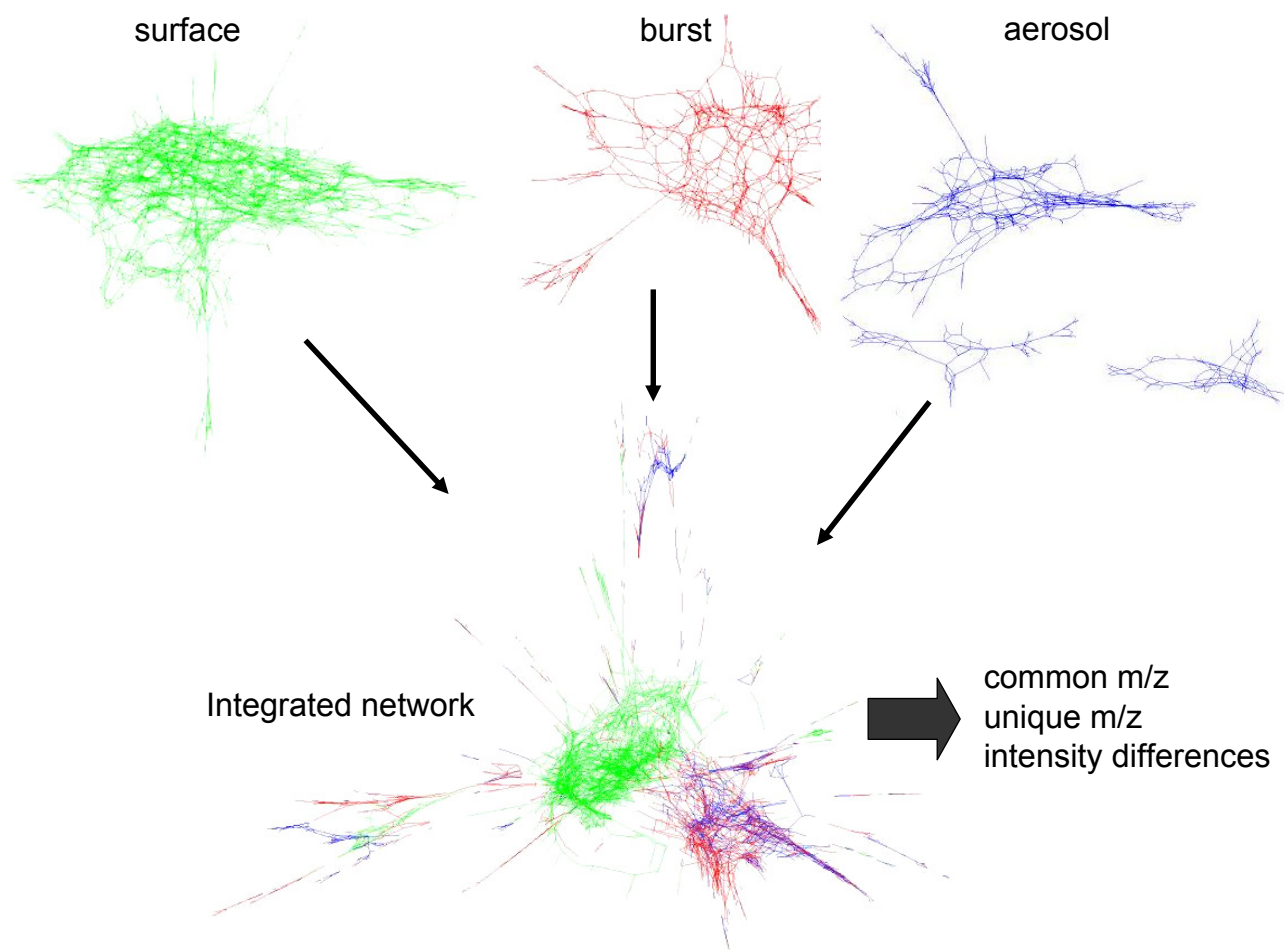

Fig. 6. Compositional network representation of the mass differences connected with $\mathrm{m} / \mathrm{z}$, showing the looser network in the order surface/burst/aerosol and their integration in the final network enabling to filter the common, unique signals for process description. 

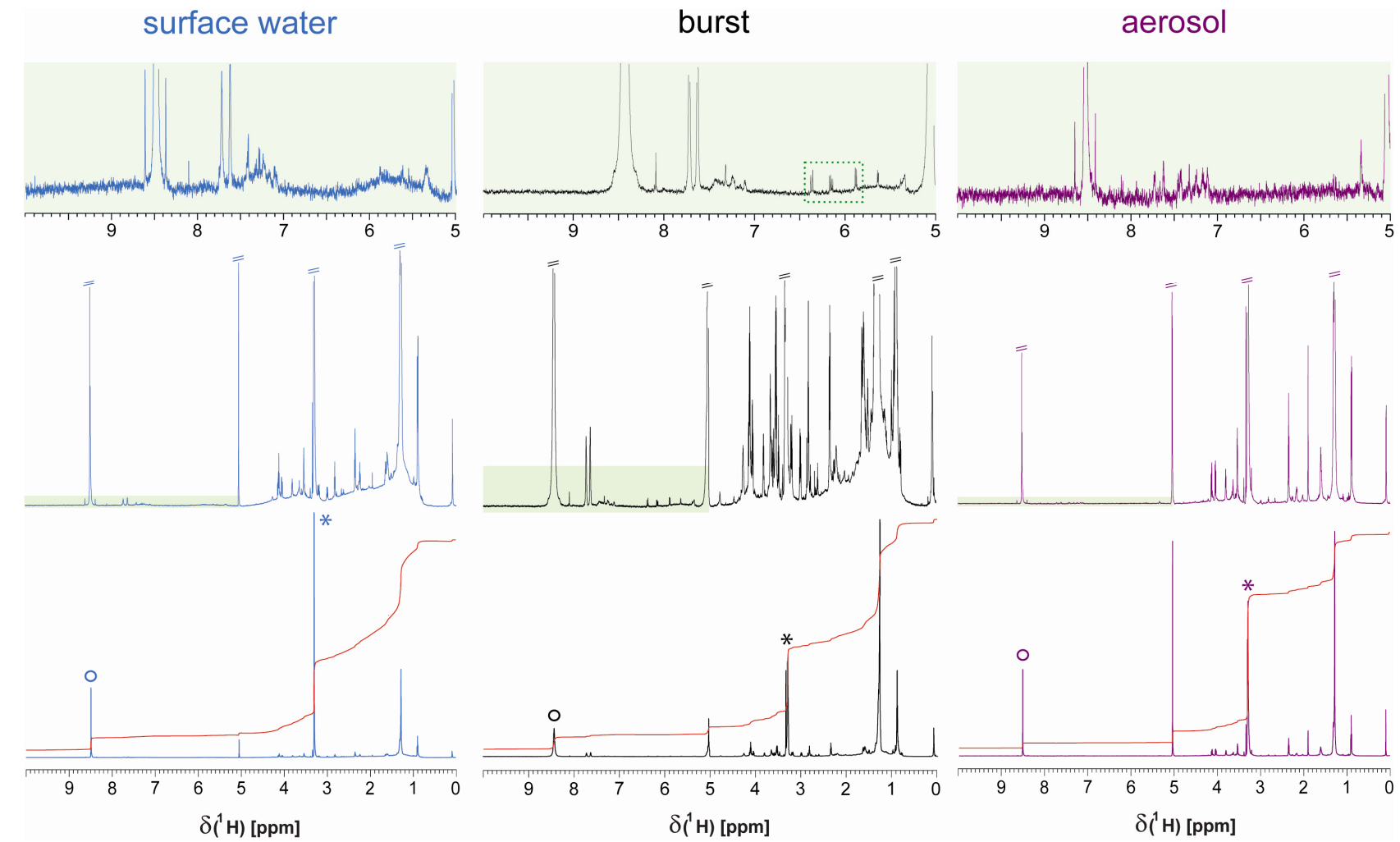

Fig. 7. $500 \mathrm{MHz}{ }^{1} \mathrm{H}$ NMR spectra of surface water, burst, and aerosol in $\mathrm{CD}_{3} \mathrm{OD}\left(\delta_{\mathrm{H}}=3.30 \mathrm{ppm}\right.$; asterisk $)$. Bottom panel: entire spectrum $\left(\delta_{\mathrm{H}}=0 \ldots 10 \mathrm{ppm}\right)$ with (middle panel) vertical expansion with identical chemical shift scale. Top panel: expanded section of unsaturated $\left(\delta_{\mathrm{H}}=5 \ldots 10 \mathrm{ppm}\right)$ proton chemical environments with individual intensity adjustments (cf. green highlighted rectangles) to reveal also molecules of little abundance. Note the intensity ratio of the formic acid $\underline{\mathrm{HCOOH}}\left(\delta_{\mathrm{H}}=8.52 \mathrm{ppm}\right.$; circle $)$ NMR peak compared with the other signals; the two adjacent signals are the ${ }^{13} \mathrm{C}$ satellites $\left[{ }^{1} \mathrm{~J}\left({ }^{13} \mathrm{C}-{ }^{1} \mathrm{H}\right)=191 \mathrm{~Hz}\right]$ with $0.5 \%$ abundance of the central signal. Green dotted box shows chemical shift range indicated in Fig. 8, panel B.

water and of near equal abundance in aerosol and in burst (Fig. 7, Table 1).

When comparing the spectra, total aliphatics $\left(\delta_{\mathrm{H}} \sim 0.5 \ldots 1.9 \mathrm{ppm}\right)$ grew in the order surface water $<$ aerosols $\approx$ burst. However, polymethylene contributed most to aerosols, whereas a large diversity of "pure" aliphatics occurred in burst. The water sample showed a specific underlying broad hump characteristic of CRAM, which contributed to most of the section integral from $\delta_{\mathrm{H}} \sim 1.9 \ldots 3.1 \mathrm{ppm}$.

Several of the aliphatic NMR resonances occurred in all three samples (Fig. 8) and a single COSY of sample burst could reveal major connectivity patterns. Intra-aliphatic cross peaks $\left(\delta_{\mathrm{H}} \sim 0.8 \ldots 1.8 \mathrm{ppm}\right)$ were common and bound to carbonyl derivatives and other functionalized aliphatics. Aliphatics connected to oxygenated units (C- $\underline{\mathbf{H C}}-\underline{\mathbf{H C}}-\mathrm{O}-)$ were less common than molecules with connectivities within oxygenated systems (e.g. Y-O-CH-CH-O-Z, with arbitrary substitution for $\mathrm{Y}$ and $\mathrm{Z}$ ). Burst sample showed conspicuous olefinic NMR peaks that were not present in the aerosol filter sample, but visible in the surface water. Based on Jcouplings and chemical shift characteristics, this spin system was assigned as acrylic acid. Acrylic acid is a bacterial cleavage product of DMSP (dimethylsulfoniopropionate), a ubiquitous osmoprotectant in marine biota (Yoch, 2002) to DMS (dimethylsulfide). DMSP was shown having a bio-signaling effect in the marine food web with antibacterial activities at higher concentrations (Zimmer and Butman, 2000) and has a moderate photostability leading to polyethylene type of photoproducts (Bajt et al., 1997). This study also found selective enrichment of acrylic acid in the sea spray relative to sea water; its further photodegradation in the aerosol aqueous phase could lead to oxidized aliphatic structures in primary and secondary organic aerosols.

The molecular compositions and their $\mathrm{H} / \mathrm{C}$ and $\mathrm{O} / \mathrm{C}$ elemental ratios, which increased in intensity from surface via bursts to aerosols, were determined and visualized in Fig. 9 . These compounds that were continuously concentrated from the marine surface to the atmosphere had particularly low masses $(\mathrm{m} / z<300)$ involving mainly $\mathrm{CHO}$ and $\mathrm{CHNO}$ compounds. These masses were checked as possible biosignatures using the MassTRIX annotation web server available for metabolomics (Suhre and Schmitt-Kopplin, 2008). The annotated $\mathrm{m} / \mathrm{z}$ mainly corresponded to the pathways of 
Table 1. NMR section integrals (in percent to total NMR integral) according to coarse substructures given.

\begin{tabular}{|c|c|c|c|c|c|c|c|c|c|c|}
\hline$\delta\left({ }^{1} \mathrm{H}\right)[\mathrm{ppm}]$ & $10-7.5$ & $7.0-5.1$ & $4.9-3.1$ & $3.1-1.9$ & $1.9-1.35$ & $1.35-1.25$ & $1.25-0.5$ & $\begin{array}{c}\text { ratio } \\
\underline{\mathrm{H}}_{3} \mathrm{C} /\left(\mathrm{CH}_{2}\right)_{n}\end{array}$ & $\begin{array}{c}\text { ratio } \\
\underline{\mathrm{H}}_{3} \mathrm{C} / \underline{\mathrm{HC}}-\mathrm{C}-\mathrm{O}-\end{array}$ & $\begin{array}{c}\text { sum } \\
1.9-0.5 \mathrm{ppm}\end{array}$ \\
\hline Key substructures & $\begin{array}{r}\underline{\mathrm{H}}_{\mathrm{ar}}, \\
\underline{\mathrm{HCOOH}}^{\mathrm{a}}\end{array}$ & $\begin{array}{r}\mathrm{C}=\mathrm{CH} \\
\mathrm{O}_{2} \underline{\mathrm{C}} \underline{\mathrm{H}}\end{array}$ & $\underline{\mathrm{HCO}}^{\mathrm{b}}$ & $\begin{array}{r}\underline{\mathrm{HC}-\mathrm{N}}, \\
\underline{\mathrm{HC}}-\mathrm{C}-\mathrm{O}\end{array}$ & $\underline{\mathrm{HC}}-\mathrm{C}-\mathrm{C}-\mathrm{O}$ & $\left(\underline{\mathrm{CH}}_{2}\right)_{n}$ & $\underline{\mathrm{H}}_{3} \mathrm{C}-\mathrm{C}-\mathrm{C}$ & & & \\
\hline Surface water & 8.6 & 0.7 & 15.0 & 17.1 & 14.4 & 31.3 & 13.0 & 0.42 & 0.90 & 58.7 \\
\hline Burst & 9.0 & 0.9 & 10.5 & 10.6 & 11.8 & 38.6 & 18.7 & 0.49 & 1.58 & 69.0 \\
\hline Day aerosol & 6.4 & 0.2 & 15.2 & 10.0 & 8.9 & 48.5 & 10.8 & 0.22 & 1.21 & 68.2 \\
\hline
\end{tabular}

${ }^{\text {a }}$ Formic acid $\mathrm{HCOOH}\left(\delta_{\mathrm{H}}=8.52 \mathrm{ppm}\right)$ is a major contributor in this section. ${ }^{\mathrm{b}}$ Section integral excluded $\mathrm{HD}_{2} \mathrm{COD}$ NMR resonance at $\delta_{\mathrm{H}}=3.30 \mathrm{ppm}$.
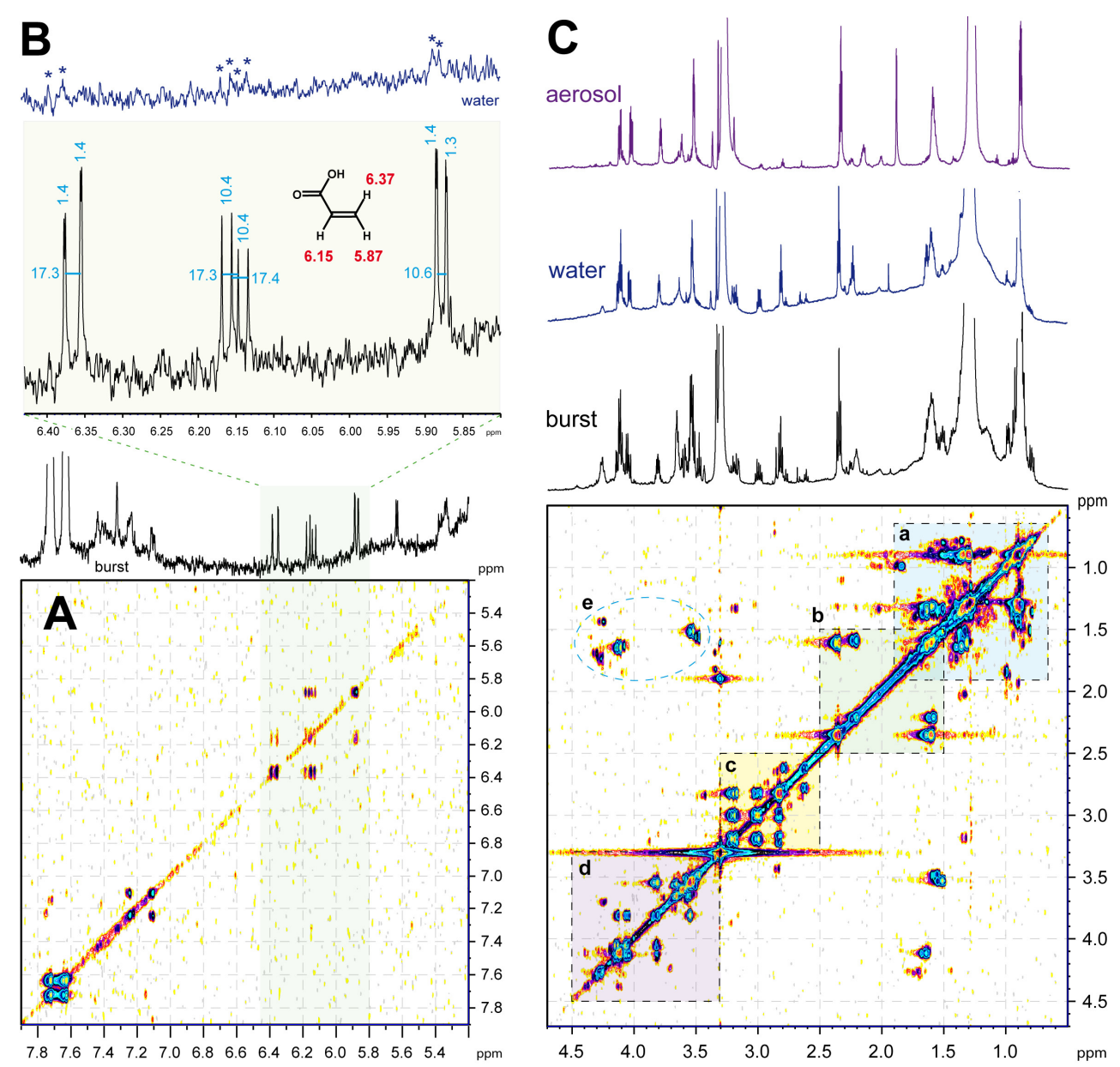

Fig. 8. $500 \mathrm{MHz}$ NMR spectra of surface water, burst, and aerosol in $\mathrm{CD}_{3} \mathrm{OD}\left(\delta_{\mathrm{H}}=3.30 \mathrm{ppm}\right)$. (A): section of unsaturated protons with an olefinic spin system tentatively assigned as acrylic acid (red: chemical shifts [ppm], blue: J couplings [Hz]); a few neutral aromatics resonate from $\delta_{\mathrm{H}} \sim 7.1 \ldots 7.4 \mathrm{ppm}$; the large NMR peaks at $\delta_{\mathrm{H}} \sim 7.6 \ldots 7.8 \mathrm{ppm}$ represent exchangeable protons, likely from phenolics or peptides. (B): section of unsaturated protons in ocean surface water, indicating small amounts of acrylic acid (asterisks); small $\mathrm{pH}$ variations cause minor chemical shift displacement with respect to those of burst sample shown in (A). (C): aliphatic section of ${ }^{1} \mathrm{H},{ }^{1} \mathrm{H} \mathrm{COSY}$ NMR spectrum of marine burst sample together with ${ }^{1} \mathrm{H}$ NMR projection spectra of burst, surface water and aerosol and key substructures indicated. Section a: intra aliphatic HC- $\underline{H} C-\underline{H C}-\mathrm{CH}$ cross peaks with methyl $\left(\delta_{\mathrm{H}}<1 \mathrm{ppm}\right)$ and within branched aliphatics; section b: functionalized aliphatics connected with carbonyl derivatives $\mathrm{C}-\underline{\mathrm{HC}}-\underline{\mathrm{HC}}-\mathrm{COX}(\mathrm{COX}=\mathrm{COOH}, \mathrm{COOR}, \mathrm{CONH})$; note the absence for cross peaks further downfield from $\left(\delta_{\mathrm{H}}>2.4 \mathrm{ppm}\right)$, which excludes oxygenated spin systems ( $\left.\mathrm{HC}-\mathrm{O}-\right)$; section c: functionalized molecule with several remote heteroatoms Z-C- $\underline{H C}-\mathrm{C} \underline{H}-\mathrm{C}-\mathrm{O}[\mathrm{Z}=\mathrm{O}(\mathrm{N})]$; section d: -O- $\underline{\mathrm{HC}}-\mathrm{C} \underline{\mathrm{H}}-\mathrm{O}-$ cross peaks, esters, ethers and alcohols; section e: cross peaks HC- $\underline{\mathrm{HC}}-\underline{\mathrm{HC}}-\mathrm{O}-$ connecting aliphatics with oxygenated carbon. 

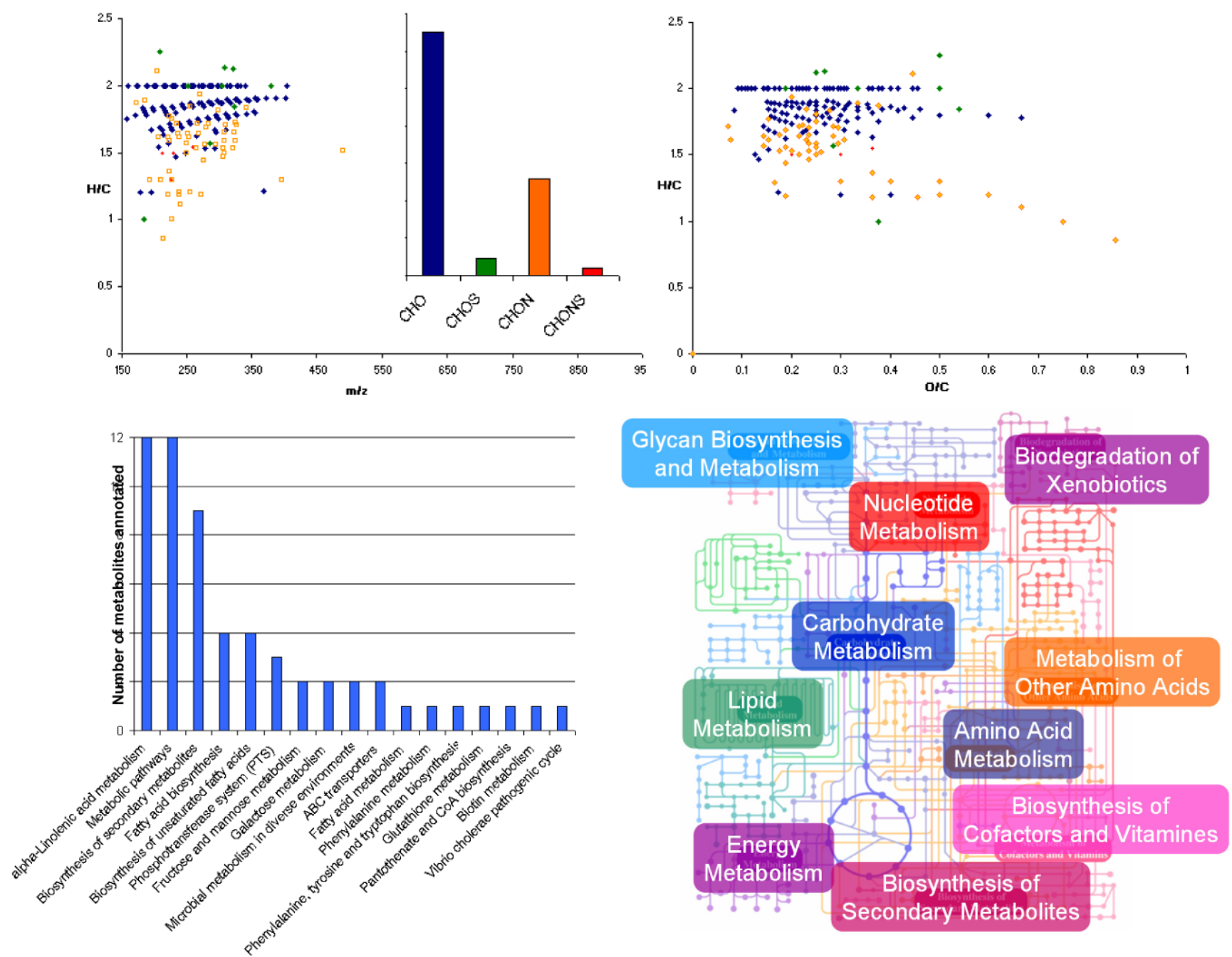

Fig. 9. Top: extracted masses common to the surface/burst/aerosol system and increased from surface towards the atmosphere represented as $\mathrm{m} / \mathrm{z}$ dependant $\mathrm{H} / \mathrm{C}$ (left) and van Krevelen diagrams (right) with corresponding CHNOS-frequency diagram. Bottom: number of metabolites found in the various metabolic pathways and symbolic illustration of the KEGG metabolic map.

alpha-linolenic acid metabolism, fatty acid biosynthesis and metabolism, biosynthesis of unsaturated fatty acids, galactose, fructose and mannose metabolism and amino acidrelated biosynthesis and metabolism (Fig. 9). About 120 masses were gradually enriched from the surface ocean into the atmospheric system and represented over 1000 isomers in MassTRIX, commonly with fatty acid type of structures within the mass range from $m / z 150$ to 490 . This group included homologous series of oxo-fatty acids, hydroxyfatty acids, mono-, di- and tricarboxylic acids, epoxy fatty acids, unsaturated fatty acids, primary and secondary alcohols, sugars, monoterpenes, methyl-branched fatty acids, straight chain fatty acids, methoxy-fatty acids, and glycerols. All these molecules show high aliphaticity and bear a polar or charged group, providing them with a higher surface activity that enables them to participate in the formation of the organic surface microlayer. Recently, ultrahigh resolution mass spectrometry (FT-ICR MS) enabled us to discriminate hundreds of biochemical components (based on accurate exact mass analysis and database search) that are preferentially partitioning into the droplets ejected from Champagne; in comparison with the bulk liquid, the droplets following bubble collapse were definitely over-concentrated with various surface active compounds, many of them showing organoleptic interest (Liger-Belair et al., 2009). We also recently hypothesized that the organic fingerprint in marine water creates a specific smell, which serves the olfactory orientation of marine animals.

The biomolecules of the surface water leave a specific molecular fingerprint in the aerosol. Own recent results show that the regional qualitative variations in dissolved organic carbon (DOC) composition found in the surface water corresponded roughly to Longhurst ecological provinces of the sea (Longhurst, 2007) and were, in addition, partially reflected in 
the aerosols released (work in progress, Koch and Kattner, 2012; Schmitt-Kopplin, 2012). We showed, in this study specifically on one specific site as well as on average across all the data of the cruise, that these compounds were preferentially concentrated in aerosols with a specific N- and Spartitioning and contribute largely to the formation of primary organic aerosols (POA) in the atmosphere. The biozone regional water biogeochemistry may thus have a direct impact on regional to global scales within possible lateral ocean-ocean or ocean-land transport of organic compounds in POA. Up to now, the transport and the effect of inorganic salts rather than of organic compounds on the global climate have been intensively studied (Facchini et al., 2008a, b). Studies related to the effect of marine POA in atmospheric chemistry are very scarce (Eckström et al., 2010) and limited to low molecular weight organic compounds, as most of the water soluble higher molecular weight and colloidal organic carbon remain uncharacterized (Rinaldi et al., 2010). The organic geochemistry of the oceans certainly will benifit from the technological developments observed in life sciences and in the near future, approaches of Metabolomics and Systems Biology certainly will complement the already started Ocean Metagenome and Ocean Microbiome projects in unraveling the Ocean's Meta-Metabolome.

\section{Conclusions}

We described the structure discriminating transfer of DOM from marine surface water into the atmosphere via bubble bursting processes. This involves adsorptive bubble separation processes leading to a preferential concentration of surface active compounds in the bubble jets drop. These jet drops are conveyed into the atmosphere and form the main part of marine primary organic aerosols. Many surface active biomolecules were found to be selectively concentrated from the surface water through the simulated sea spray into the aerosol phase. Acrylic acid was also concentrated into the sea spray and probably further photodegraded into oxidized aliphatic compounds, such as found in the aerosol SOA. Ongoing studies will integrate this information into a global description of the transfer processes, leading to representative marine primary aerosols with structural fingerprints indicative of the biogeography and biogeochemistry of the corresponding water masses.

Edited by: G. Herndl

\section{References}

Backleh-Sohrt, M., Ekici, P., Leupold, G., and Parlar, H.: Efficiency of foam fractionation for the enrichment of nonpolar compounds from aqueous extracts of plant materials, J. Nat. Prod., 68, 13861389, 2005.
Bajt, O., Sket, B., and Faganeli, J.: The aqueous photochemical transformation of acrylic acid, Mar. Chem., 58, 255-259, 1997.

Barger, W. R. and Garret, W. D.: Surface-active organic material in the marine atmosphere, J. Geophys. Res., 75, 4561-4566, 1970.

Blanchard, D. C.: Surface-active monolayers, bubbles, and jet drops, Tellus B, 42, 200-205, 1990.

Bird, J. C., de Ruiter, R., Courbin, L., and Stone, H. A.: Daughter bubble cascades produced by folding of ruptured thin films, Nature, 465, 759-762, 2010.

Ekström, S., Nozière, B., Hultberg, M., Alsberg, T., Magnér, J., Nilsson, E. D., and Artaxo, P.: A possible role of ground-based microorganisms on cloud formation in the atmosphere, Biogeosciences, 7, 387-394, doi:10.5194/bg-7-387-2010, 2010.

Facchini, M. C., Decesari, S., Rinaldi, M., Carbone, C., Finessi, E., Mircea, M., Fuzzi, S., Moretti, F., Tagliavini, E., Ceburnis, D., and O'Dowd, C. D.: Important source of marine secondary organics aerosol from biogenic amines, Environ. Sci. Technol., 42, 9116-9121, 2008a.

Facchini, M. C., Rinaldi, M., Decesari, S., Carbone, C., Finessi, E., Mircea, M., Fuzzi, S., Ceburnis, D., Flanagan, R., Nilsson, E. D., de Leeuw, G., Martino, M., Woeltjen, J., and O'Dowd, C. D.: Primary submicron marine aerosol dominated by insoluble organic colloids and aggregates, Geophys. Res. Lett., 35, L17814, doi:10.1029/2008GL034210, 2008b.

Hertkorn, N., Benner, R., Schmitt-Kopplin, P., Kaiser, K., Kettrup, A., and Hedges, I. J.: Characterization of a major refractory component of marine organic matter, Geochim. Cosmochim. Acta., 70, 2990-3010, 2006.

Hertkorn, N., Ruecker, C., Meringer, M., Gugisch, R., Frommberger M., Perdue, E. M., Witt, M., and Schmitt-Kopplin, Ph.: High-precision frequency measurements: indispensable tools at the core of the molecular-level analysis of complex systems, Anal. Bioanal. Chem., 389, 1311-1327, 2007.

Hertkorn, N., Frommberger, M., Witt, M., Koch, B., SchmittKopplin Ph., and Perdue, E. M.: Natural Organic Matter and the Event Horizon of Mass Spectrometry, Anal. Chem., 80, 89081919, 2008.

Hertkorn, N., Harir, M., Koch, B. P., Michalke, B., Grill, P., and Schmitt-Kopplin, P.: High field NMR spectroscopy and FTICR mass spectrometry: powerful discovery tools for the molecular level characterization of marine dissolved organic matter from the South Atlantic Ocean, Biogeosciences Discuss., 9, 745-833, doi:10.5194/bgd-9-745-2012, 2012.

Koch, B. P. and Kattner, G.: Preface "Sources and rapid biogeochemical transformation of dissolved organic matter in the Atlantic Surface Ocean”, Biogeosciences, in prep., 2012.

Liger-Belair, G.: The science of bubbly, Sci. Am., 288, 80-85, 2003.

Liger-Belair, G., Marchal, R., Robillard, B., Dambrouck, T., Maujean, A., Vignes-Adler, M., and Jeandet, P.: On the velocity of expanding spherical gas bubbles rising in-line in supersaturated hydroalcoholic solutions: Application to bubble trains in carbonated beverages, Langmuir, 16, 1889-1895, 2000.

Liger-Belair, G., Lemaresquier, H., Robillard, B., Duteurtre, B., and Jeandet, P.: The secrets of fizz in champagne wines: A phenomenological study, Am. J. Enol. Vitic., 52, 88-92, 2001.

Liger-Belair, G., Cilindre, C., Gougeon, R., Lucio, M., Gebefügi, I., Jeandet, P., and Schmitt-Kopplin, P.: Unraveling different chemical fingerprints between a champagne wine and its aerosols, $\mathrm{P}$. 
Natl. Acad. Sci. USA, 106, 16545-16549, 2009.

Longhurst, A. R.: Ecological geography of the sea, Academic Press San Diego, 2007.

MacIntyre, F.: Flow patterns in breaking bubbles, J. Geophys. Res., 77, 5211-5228, 1972.

Mukerjee, P. and Handa, T.: Adsorption of fluorocarbon and hydrocarbon surfactants to air-water, hexane-water, and perfluorohexane-water interfaces: Relative affinities and fluorocarbon-hydrocarbon nonideality effects, J. Phys. Chem. 85, 2298-2303, 1981.

O'Dowd, C. D. and de Leeuw, G.: Marine aerosol production: A review of the current knowledge, Philos. T. R. Soc., 365, 20072043, 2007.

O’Dowd, C. D., Facchini, M. C., Cavalli, F., Ceburnis, D., Mircea, M., Decesari, S., Fuzzi, S., Yoon, Y. J., and Putaud, J. P.: Biogenically driven organic contribution to marine aerosol, Nature, 431, 676-680, 2004.

Oppo, C., Bellandi, S., Innocenti, N., Stortini, A., Loglio, G., Schiavuta, E., and Cini, R.: Surfactant components of marine organic matter as agents for biogeochemical fractionation and pollutant transport via marine aerosols, Mar. Chem., 63, 235-253, 1999.

Péron, N., Cagna, A., Valade, M., Bliard, C., Aguié-Béghin, V., and Douillard, R.: Layers of macromolecules at the champagne/air interface and the stability of champagne bubbles, Langmuir, 17, 791-797, 2001.

Péron, N., Meunier, J., Cagna, A., Valade, M., and Douillard, R.: Phase separation in molecular layers of macromolecules at the champagne-air interface, J. Microscopy, 214, 89-98, 2004.

Piel, C., Weller R., Huke, M., and Wagenbach, D.: Atmospheric methane sulfonate and non-sea-salt sulfate records at the European Project for Ice Coring in Antarctica (EPICA) deep-drilling site in Dronning Maud Land, Antarctica, J. Geophys. Res., 111, D03304, doi:10.1029/2005JD006213, 2006.

Resch, F. J., Darrozes, J. S., and Afeti, G. M.: Marine liquid aerosol production from bursting of air bubbles, J. Geophys. Res., 91, 1019-1029, 1986.

Rinaldi, M., Decesari, S., Finessi, E., Giulianelli, L., Carbone, C., Fuzzi, S., O'Dowd, C. D., Ceburnis, D., and Facchini, M. C.: Primary and secondary organic marine aerosol and oceanic biological activity: Recent results and new perspectives for future studies, Hindawi Publishing Corporation, Advances in Meteorology, 2010, 310682, doi:10.1155/2010/310682, 2010.
Schmitt-Kopplin, P., Gelencsér, A., Dabek-Zlotorzynska, E., Kiss, G., Hertkorn, N., Harir, M., Hong, Y., and Gebefügi, I.: Analysis of the unresolved organic fraction in atmospheric aerosols with ultrahigh resolution mass spectrometry and nuclear magnetic resonance spectroscopy: Organosulfates as photochemical smog constituents, Anal. Chem., 82, 8017-8026, 2010.

Spiel, D. E.: The number and size of jet drops produced by air bubbles bursting on a fresh water surface, J. Geophys. Res., 99, 10289-10296, 1994.

Spiel, D. E.: On the birth of jet drops from bubbles bursting on water surfaces, J. Geophys. Res., 100, 4995-5006, 1995.

Spiel, D. E.: More on the births of jet drops from bubbles bursting on seawater surfaces, J. Geophys. Res., 102, 5815-5821, 1997.

Suhre, K. and Schmitt-Kopplin, P.: MassTRIX: mass translator into pathways, Nucleic Acids Res., 36, W481-W484, doi:10.1093/nar/gkn194, 2008.

Tseng, R. S., Viechnicki, J. T., Skop, R. A., and Brown, J. W.: Seato-air transfer of surface-active organic compounds by bursting bubbles, J. Geophys. Res., 97, 5201-5206, 1992.

Tziotis, D., Hertkorn, N., and Schmitt-Kopplin, P.: Kendrickanalogous network visualisation of Ion Cyclotron Resonance Fourier Transform (FTICR) Mass Spectra: Improved options to assign elemental compositions and to classify organic molecular complexity, Eur. J. Mass Spectrom., 17, 415-421, 2011.

Woodcock, A. H., Kientzler, C. F., Arons, A. B., and Blanchard, D. C.: Giant condensation nuclei from bursting bubbles, Nature, 172, 1144-1145, 1953.

$\mathrm{Wu}$, J.: Evidence of sea spray produced by bursting bubbles, Science, 212, 324-326, 1981.

Xie, Z., Koch, B. P., Möller, A., Sturm, R., and Ebinghaus, R.: Transport and fate of hexachlorocyclohexanes in the oceanic air and surface seawater, Biogeosciences, 8, 2621-2633, doi:10.5194/bg-8-2621-2011, 2011.

Yoch, D. C.: Dimethylsulfoniopropionate: its source, role in the marine food web, and biological degradation to dimethylsulfide, Appl. Environ. Microbiol., 68, 5804-5815, 2002.

Zimmer, R. K. and Butman, C. A.: Chemical signaling processes in the marine environment, Biol. Bull., 198, 168-187, 2000. 